\title{
Follow-Up Support for Effective type 1 Diabetes self-management (The FUSED Model): A systematic review and meta- ethnography of the barriers, facilitators and recommendations for sustaining self- management skills after attending a structured education programme
}

Fiona Campbell ${ }^{1 *} \mathbb{D}$, Julia Lawton², David Rankin², Mark Clowes', Elizabeth Coates ${ }^{1}$, Simon Heller ${ }^{4}$, Nicole de Zoysa ${ }^{3}$, Jackie Elliott ${ }^{4}$ and Jenna P. Breckenridge ${ }^{5}$

\begin{abstract}
Background: People with type 1 diabetes who attend structured education training in self-management using flexible intensive therapy achieve improved blood glucose control and experience fewer episodes of severe hypoglycaemia. However, many struggle to sustain these improvements over time. To inform the design of more effective follow-up support we undertook a review of qualitative studies which have identified factors that influence and inform participants' self-management behaviours after attending structured education and their need for support to sustain improvements in glycaemic control.

Methods: We undertook a meta-ethnography of relevant qualitative studies, identified using systematic search methods. Studies were included which focused on participants' experiences of self-managing type 1 diabetes after attending structured education which incorporated training in flexible intensive insulin therapy. A line of argument approach was used to synthesise the findings.

Results: The search identified 18 papers from six studies. The studies included were judged to be of high methodological quality. The line of argument synthesis developed the Follow-Up Support for Effective type 1 Diabetes self-management (FUSED) model. This model outlines the challenges participants encounter in maintaining diabetes self-management practices after attending structured education, and describes how participants try to address these barriers by adapting, simplifying or personalising the self-management approaches they have learned. To help participants maintain the skills taught during courses, the FUSED model presents ten recommendations abstracted from the included papers to provide a logic model for a programme of individualised and responsive follow-up support.

(Continued on next page)
\end{abstract}

\footnotetext{
* Correspondence: f.campbell@sheffield.ac.uk

'School of Health and Related Research (ScHARR), University of Sheffield,

Regent Court, 30 Regent Street, S1 4DA Sheffield, England

Full list of author information is available at the end of the article
}

(c) The Author(s). 2018 Open Access This article is distributed under the terms of the Creative Commons Attribution 4.0 International License (http://creativecommons.org/licenses/by/4.0/), which permits unrestricted use, distribution, and reproduction in any medium, provided you give appropriate credit to the original author(s) and the source, provide a link to the Creative Commons license, and indicate if changes were made. The Creative Commons Public Domain Dedication waiver (http://creativecommons.org/publicdomain/zero/1.0/) applies to the data made available in this article, unless otherwise stated. 


\begin{abstract}
(Continued from previous page)
Conclusions: This meta-ethnography highlights how providing skills training using structured education to people with type 1 diabetes does not necessarily result in participants adopting and sustaining recommended changes in behaviour. To help people sustain diabetes self-management skills after attending structured education, it is recommended that support be provided over the longer-term by appropriately trained healthcare professionals which is responsive to individuals' needs. Although developed to inform support for people with type 1 diabetes, the FUSED model provides a framework that could also be applied to support individuals with other long term conditions which require complex self-management skills to be learned and sustained over time.
\end{abstract}

Trial registration: PROSPERO registration: CRD42017067961.

Keywords: Type 1 diabetes, Self-management, DAFNE, Structured education, Meta-ethnography, Qualitative evidence synthesis, FUSED

\section{Background}

Type 1 diabetes mellitus (T1DM) is a chronic metabolic disease, characterized by hyperglycemia, which develops when the pancreas stops producing insulin due to auto-immune destruction of the $\beta$ cells [1]. Global incidence rates are increasing at approximately $3-4 \%$ per year [2]. If not managed optimally, T1DM can lead to an increased risk of cardiovascular disease, microvascular complications [3] and premature death $[4,5]$. Reaching and maintaining the glucose levels necessary to prevent complications requires the acquisition of a number of complex skills. Achieving these glucose targets also brings with it an increased risk of hypoglycaemia due to the limitations of subcutaneous insulin delivery. As a result, many people struggle to achieve optimal glycaemic control; hence, diabetes self-management education/training is now considered a critical element of care [6].

Education programmes for people with diabetes have evolved from didactic approaches, where knowledge is imparted by health professionals, to theoretically-informed structured education programmes (SEPs) incorporating group interaction, experiential learning, skills-based training and problem-solving in order to promote self-care $[7,8]$. Concurrent with these developments, more flexible approaches to diabetes self-management have been promoted. This includes flexible intensive insulin therapy (FIIT) which is now widely recommended for type 1 diabetes self-management. FIIT comprises long-acting basal insulin injected once or twice daily, and bolus doses of quick acting insulin adjusted to take into account the carbohydrate content of snacks and meals. Individuals using FIIT are advised to perform regular self-monitoring of blood glucose levels (normally undertaken pre-meal and pre-bed). To calculate appropriate quick acting insulin doses, they are taught how to estimate the carbohydrate content of meals and snacks and, using ratios, to adjust doses in ways which also take account of their current blood glucose reading and the results of previous tests. To help people achieve clinically recommended blood glucose target ranges, they are also given instruction on how to use corrective doses of insulin to counter high blood glucose readings and how to consume carbohydrate in the correct amounts to address low blood glucose. Instruction is also given on how to interpret patterns and/or changes in blood glucose readings collected over time to ascertain whether to adjust mealtime ratios or basal insulin doses in order to maintain blood glucose within clinically-recommended target ranges $[9,10]$.

Developed in Düsseldorf, at the Diabetes Treatment and Teaching Programme (DTTP) [11], FIT is a fundamental component of SEPs in countries around the world [12], many of which are based on the Düsseldorf model [11]. This includes the Dose Adjustment for Normal Eating (DAFNE) programme [13, 14], which is recommended for all adults with T1DM in the UK [15]. Research exploring DAFNE, and other SEPs for people with T1DM has reported short and medium term improvements in HbA1c and quality of life, and reductions in incidence of severe hypoglycaemia [13, 16-21]. However, while improvements in quality of life are generally maintained, people frequently experience a decline in their glycaemic control over time, which suggests they are unable to sustain FIIT self-management practices in the long-term [18, 21, 22]. The reasons for declines in glycaemic control are poorly understood [23], which has prompted calls for research to be undertaken to better understand participants' experiences after attending SEPs [14]. This has led to various studies being undertaken to better understand the challenges people with T1DM encounter when sustaining a FIIT approach following SEPs and to identify their longer-term information and support needs. However, to our knowledge, there have been no reviews of studies exploring participants' experiences after FIIT training to help them maintain skills taught during SEPs and sustain improvements in glycaemic control. To design effective follow-up support, it is necessary to identify factors that influence and inform self-management behaviours in people with T1DM following participation in a SEP, and their experiences of follow-up support and how this might be improved. 


\section{Methods}

The aim of this paper was to a) synthesise from existing qualitative literature, the experiences and views of people with T1DM about sustaining learning and selfmanagement skills after attending a SEP providing training in FIIT and b) to identify recommendations for follow-up support provision. The work comprised the first phase of a larger study to develop and trial a new structured education programme and follow-up support package for people with T1DM, called 'DAFNEplus' [24]. We sought to develop an evidence informed model to guide intervention design, setting out to address the following objectives

1. To describe the scope, nature and quality of the qualitative research exploring how people with T1DM apply and sustain learning and selfmanagement skills after attending a SEP.

2. To identify the barriers and facilitators to applying and sustaining learning and self-management skills after attending a SEP.

3. To explore what follow-up support has been provided, how acceptable it has been and whether it helped people with T1DM to apply and sustain learning and self-management skills after attending a SEP.

4. To identify what recommendations have been made about follow-up support provision to best support people with T1DM to apply and sustain selfmanagement skills taught on a SEP.

We employed Noblit and Hare's [25] seven stage meta-ethnographic approach as this has been used successfully by others to develop theory to underpin practice interventions [26]. Meta-ethnography goes beyond describing or summarising literature, to deriving new interpretations that are grounded in, but extend beyond, individual empirical studies [27]. Meta-ethnography seeks to develop a coherent theory that is economical (it explains what is going on in the literature in the simplest way), cogent (the explanation is achieved without redundancy, ambiguity and contradiction), and credible (it is useful and relevant for the intended audience) [25]. Therefore, in addition to offering new conceptual insights to inform the wider type 1 diabetes evidence base, we anticipated that a meta-ethnographic approach would enable us to directly inform design and evaluation of a new follow-up intervention to be delivered as part of the 'DAFNEplus' study.

\section{Stage 1 and 2: Getting started and deciding what is relevant} Stages 1 and 2 of the meta-ethnographic approach involved establishing the scope of the synthesis and locating relevant studies [25]. We conducted a systematic search to identify papers that presented empirical qualitative data about the experiences of adults with T1DM after attending a SEP. As meta-ethnography does not aim to summarise an entire body of knowledge or to draw any statistical inference, it does not necessarily pursue exhaustive search strategies typical of quantitative systematic reviews [28]. However, to identify the scope and nature of qualitative studies published about the topic (objective 1), identify any gaps in the existing evidence base and ensure that recommendations for follow-up support were drawn from all available, relevant evidence we opted to utilise a systematic search strategy.

\section{Search strategy}

Databases searched included MEDLINE, Embase, CINAHL, PsycINFO and Web of Science using a combination of subject terms and keywords, which were developed in discussion with topic experts and informed by existing literature. We used the SPIDER model [29] to support development of our search strategy (Table 1). Where available, validated search filters (developed by the HEDGES team at McMaster University) were used to restrict results to qualitative evidence [30]. We supplemented the database searches by checking the reference lists of included papers, contacting key authors, and citation tracking. Where no validated qualitative filter was available (e.g. in Web of Science), qualitative terms drawn from the Medline filters were used to search within the database. Searches used a combination of subject headings and free text terms occurring in titles and abstracts. The

Table 1 Terms used to develop search strategy

\begin{tabular}{|c|c|}
\hline Sample: & Adults with type 1 diabetes \\
\hline $\begin{array}{l}\text { Phenomenon of } \\
\text { Interest: }\end{array}$ & $\begin{array}{l}\text { Diabetes self-management education, patient education, patient information, structured education, specific names } \\
\text { (e.g. DAFNE, BERTIE), follow up support, health professional support, flexible intensive insulin therapy (FIIT), } \\
\text { technology }\end{array}$ \\
\hline Design: & $\begin{array}{l}\text { Grounded theory, phenomenology, ethnography, interview, focus group, observation, questionnaire, } \\
\text { thematic analysis, constant comparison, content analysis, themes, category, experience, views, perspectives }\end{array}$ \\
\hline $\begin{array}{l}\text { Evaluation/ } \\
\text { outcomes: }\end{array}$ & $\begin{array}{l}\text { Sustained behaviour change, self-management skills, BG control, glycaemic control, BG targets, BG monitor, } \\
\text { carb counting, hypo management, insulin dose adjustment, diet choices, mealtime ratios, confidence, coping }\end{array}$ \\
\hline Research: & Qualitative studies \\
\hline
\end{tabular}


Medline strategy was developed through several iterations in consultation with the larger 'DAFNEplus' project team, and also validated against known relevant articles. This search was then used as a template which was modified when searching other databases. Searches were limited to 1978 onwards to coincide with the development of the first SEP for T1DM [11]. Papers were limited to English language for pragmatic reasons. An example of our search strategy is included in Additional file 1.

\section{Screening and selection}

Titles and abstracts were screened against the inclusion and exclusion criteria (see Table 2) by two members of the review team independently. For abstracts that met the inclusion criteria, papers were retrieved in full and re-assessed against the inclusion criteria by two members of the research team to agree on final inclusion.

We observed that several papers were derived from the same studies and based on the same dataset. On appraisal of the full texts, we identified that, rather than repeating the same findings, each paper offered a distinct focus and presented different aspects of the data. We therefore took all papers forward for inclusion in recognition that they may each contribute to the synthesis in conceptually different ways.

Figure 1 provides details of the screening and selection process, as recommended by the Preferred Reporting Items for Systematic Reviews and Meta-Analyses (PRISMA) statement (http://www.prisma-statement.org). We also used guidance from the eMERGe website to inform the reporting of this meta-ethnography. [31]

\section{Stage 3: Reading the studies}

This stage involved familiarising ourselves with the content and context of the included papers and

Table 2 Inclusion and Exclusion Criteria

Inclusion
- Papers reporting qualitative data that captures the experiences
of adults with T1DM after attending a SEP teaching FIIT,
and that includes data relevant to understanding the barriers
and facilitators to sustaining self-management skills following
the SEP
- Published after 1978.
Exclusion
- Papers that present quantitative data only.
- Papers that are not explicitly about T1DM (e.g. papers where
participants may have type 1 OR type 2 , or papers which focus
on other long term conditions).
- Papers presenting data about SEPS that are not based on FIIT.
- Citations with results only published as conference abstracts
- Published in languages other than English

extracting information about key study characteristics [25, 32, 33]. Details were extracted by two authors working independently and were documented by each in a separate version of a purpose-designed matrix under the following headings: author, year, country, aims, description of intervention, participants, data collection, data analysis, and presentation of findings. Both matrices were compared and combined to ensure that all relevant characteristics were identified and described. Reading the studies also included quality appraisal, guided by the current version of the NICE (2012) manual procedures for assessment of qualitative studies [34]. Both reviewers agreed the combined assessment of each study. All studies, regardless of quality, were included in the review, with the expectation that the poorer quality studies would contribute less to the synthesis [25]. Appraising the included studies ensured careful and systematic reading of the included studies [27] and yielded descriptive information on aspects of the quality of the included papers which provided context for the meta-ethnographic synthesis.

\section{Stage 4: Determining how the studies are related}

This stage involved exploration of the relationships between the papers and identifying common concepts shared between them [25, 32, 33]. It involved making 'a list of key metaphors, phrases, ideas and/or concepts (and their relations) used in each account' [25]. Within meta-ethnography, 'metaphors' or 'concepts' refer to the meaningful, explanatory ideas expressed within the included papers. We operationalised this process by extracting, from each paper, all statements of key findings (from the findings/results sections of included papers) and statements of key recommendations (from the discussion and conclusion sections of included papers). Using an Excel spreadsheet for each paper, with the headings 'key findings' and 'recommendations', we listed the key statements from each paper. Statements were formed from either the authors' own words (where concepts were briefly and clearly described in the original paper), or from paraphrasing (where descriptions were unclear and/or lengthy).

\section{Stage 5: Translating the studies into one another}

This stage involved directly and systematically comparing concepts across individual papers [28, 35]. We compared each statement of key findings extracted in stage 4 and grouped them according to similarity, arriving at a series of higher level concepts. We then used this same process of comparison for the statements of recommendation, looking for similarities and differences and arriving at a higher level set of concepts. We purposefully kept the statements regarding findings and recommendations 


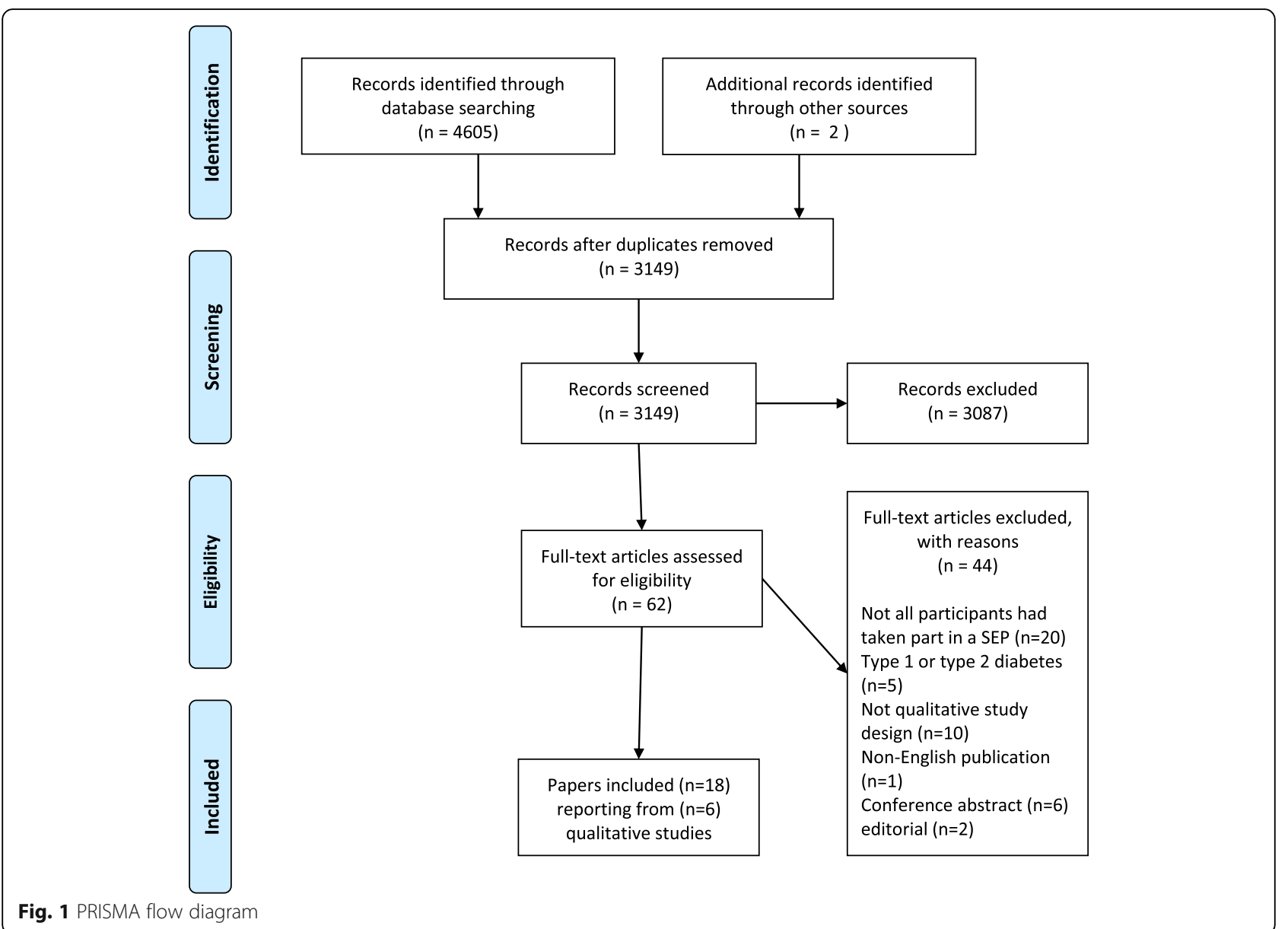

separate it order to distinguish between concepts arising directly from participant data and those developed by authors in response to the findings.

\section{Stage 6: Synthesising translations}

Noblit \& Hare [25] proposed three approaches to synthesis, depending on how the concepts from each paper relate to one another: reciprocal syntheses (where papers are conceptually similar), refutational syntheses (where papers contradict one another), line of argument synthesis (where papers identify different parts of the whole story). We identified that a line of argument synthesis would be most suitable because, while there was overlap between the papers, they each dealt with a slightly different aspect of self-management. There were no refutational findings in the included papers. The higher level concepts generated during stage 5 were systematically compared to explore how they related to one another, resulting in a coherent, logical, explanatory model. This was an iterative process until the concepts fitted together without overlap or redundancy. In addition, we also looked for and explained the inter-connections between key findings and recommendations to arrive at an integrated explanation.

\section{Stage 7: Expressing the synthesis}

The resultant line of argument takes the form of a logic model. The model provides a high level explanation about why people struggle to sustain self-management practices following attendance at a structured education programme and outlines the essential elements of effective follow-up support.

\section{Results}

Included papers

The search identified 3149 citations and following screening 64 full text papers were retrieved. A further 46 papers were excluded on reading the full text. The list of excluded studies and reason for exclusion is given in Additional file 2. Eighteen papers, reporting findings from six studies, were included in the synthesis [36-53]. Three presented findings from a longitudinal interview study involving 40 individuals who took part in a RCT in Ireland which compared group based follow-up with usual care after attending a DAFNE course [36-38]. One of these papers used mixed-methods [38], however, the qualitative data were of sufficient depth and quality for inclusion. Nine papers reported findings from a 
longitudinal interview study with 30 individuals after attending a DAFNE course in the UK [39-47]. Two papers presented findings from repeat interviews with 42 participants in the Relative Effectiveness of Pumps over Multiple Daily Injections and Structured Education (REPOSE) trial in the UK, where participants in both arms initially attended a DAFNE course [48, 49]. Two papers presented findings from a UK-based interview study involving 21 participants who had attended a DAFNE course between 3 months and 11 years previously [50, 51]. One paper presented findings from an interview study with 24 participants who had taken part in the DAFNE-HART course, which was specifically developed for people with impaired awareness of hypoglycaemia [52]. One paper presented findings from a qualitative study of seven participants' experiences of using a mobile phone app after attending a DAFNE course [53]. Table 3 provides an overview of each of the six primary studies, detailing the participants and the type of structured education and follow-up support they had received. Table 4 provides detailed information about each of the papers included in the synthesis and Table 5 presents the results of the quality assesment of each included paper.

\section{The line of argument: Follow-up support for effective type 1 diabetes self-management (the FUSED model)}

The line of argument synthesis resulted in the model presented below. The Follow-Up Support for Effective type 1 Diabetes self-management (FUSED) model synthesises - or 'fuses' together - the learning from the included qualitative studies to outline the barriers to maintaining diabetes self-management practices after attending a SEP and presents the key features of follow-up support needed to facilitate effective, sustained disease self-management. The FUSED model describes how participants finish SEPs feeling enthusiastic about self-management practices, but subsequently, encounter various challenges to realising this in everyday life after course completion. The model outlines how participants respond to these challenges by adapting, simplifying, or personalising the self-management practices they were taught on SEPs. To help future participants sustain their learning and skills, the FUSED model proposes a combination of structured and responsive follow-up support guided by ten key recommendations. The model is presented diagrammatically in Fig. 2 and each of the concepts is described and explained below. For ease of reading, the diagram and narrative description have been organised into three sections: (A) Challenges encountered after course attendance; (B) Participant response to post-course challenges; (C) Recommendations for effective follow-up support. Table 6 also summarises how each included paper has contributed to the concepts within the line of argument.

\section{A. Challenges encountered after course attendance}

Armed with new knowledge and skills, participants leave SEPs feeling empowered and better equipped to undertake effective disease self-management [36, 47, 4951]. They have a better understanding of their condition [36-38, 45, 50, 51] and having 'rules' to follow gives them greater confidence in undertaking self-management [39, 47]. Participants finish the course feeling motivated to put their new self-management skills into practice, driven by the desire to have less frequent hypoglycaemic episodes [36, 45], achieve tighter blood glucose control [39, 42, 43], prevent complications [36, 37], lower their HbA1c levels [37], and free themselves from previously restrictive treatment regimens [40, 41, 44]. Participants with impaired hypoglycaemia awareness similarly feel confident and committed to restoring awareness and implementing effective monitoring and treatment practices [52]. However, as we report below, after transitioning from the course into everyday life, all participants encounter various barriers to implementing their new knowledge and skills [47].

\section{The complexity of life}

Outside the cocooned classroom environment of SEPs, participants can feel trepidation about applying self-management practices in the complex contexts of their everyday lives $[38,39,41,50]$. Participants feel most anxious in 'untested' or non-routine situations, such as when eating out $[40,47]$, at the weekend or on holiday [41]. Those who do not lead routinized lives with predictable working patterns and regular mealtimes can struggle to integrate self-management practices into everyday life and achieve stable blood glucose [39, 41, 47]. At critical junctures, when they face illness or bereavement for example, participants can intentionally or unintentionally prioritise other areas of their lives, resulting in less rigid application of self-management practices [36, 38, 47].

\section{Disconnect between effort and reward}

Participants want tangible rewards for their self-management efforts; for example, as already noted, a reduction in hypoglycaemic episodes or reduced HbA1c levels. However, when participants experience disconnect between effort and reward, they can become demotivated and frustrated. Repeatedly failing to achieve blood glucose levels within target ranges is demoralising $[43,51]$ and can result in feelings of failure [47], which counteracts participants' initial feelings of motivation and empowerment [36]. Frustrations are even greater for participants whose glucose profiles fail to improve despite following self-management principles [36, 38], such as accurate carbohydrate counting which many find tedious [47]. Unanticipated consequences, such as gaining weight from greater dietary freedom, can also diminish the benefits of the new self-management approach [40]. 


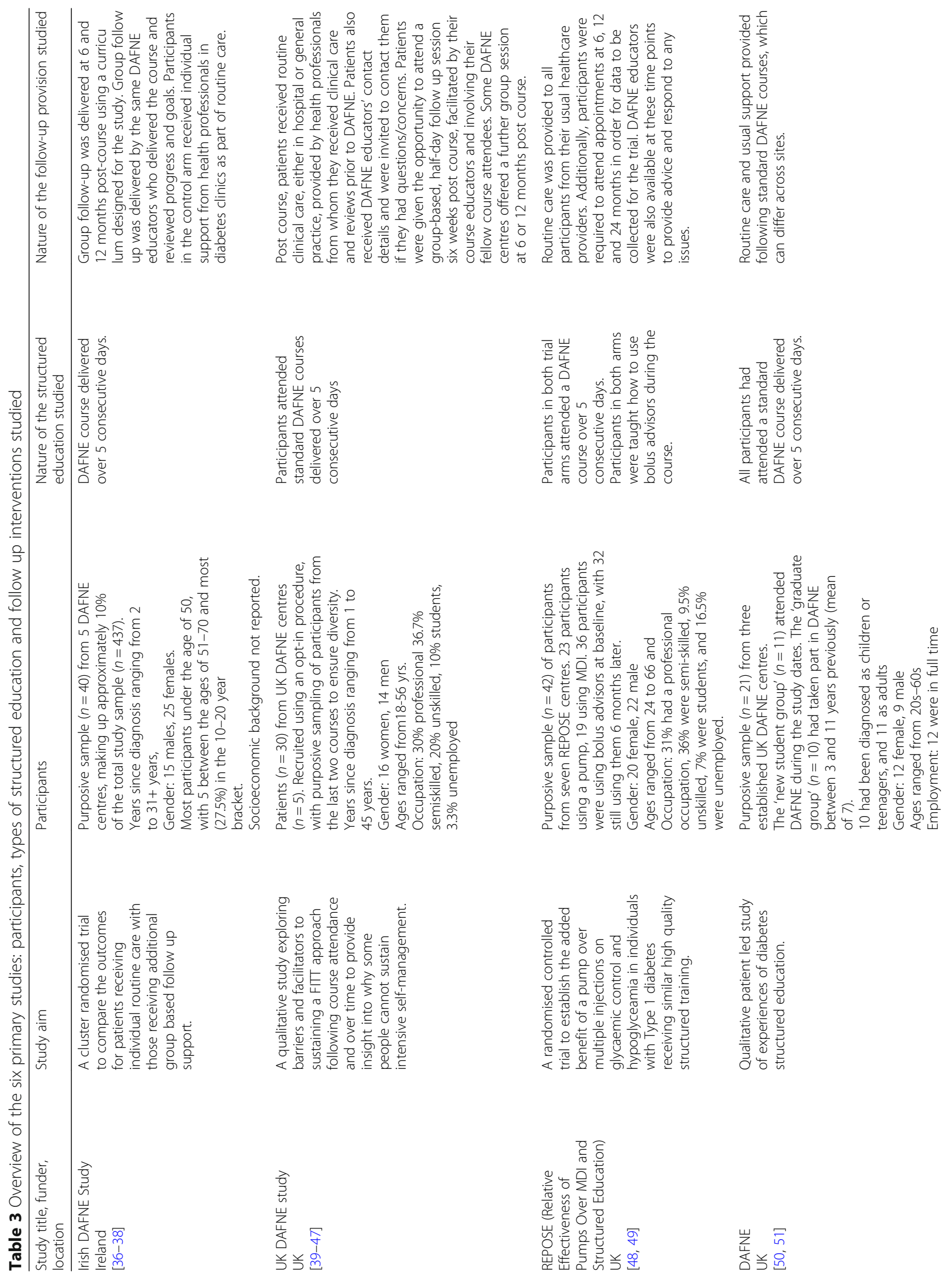




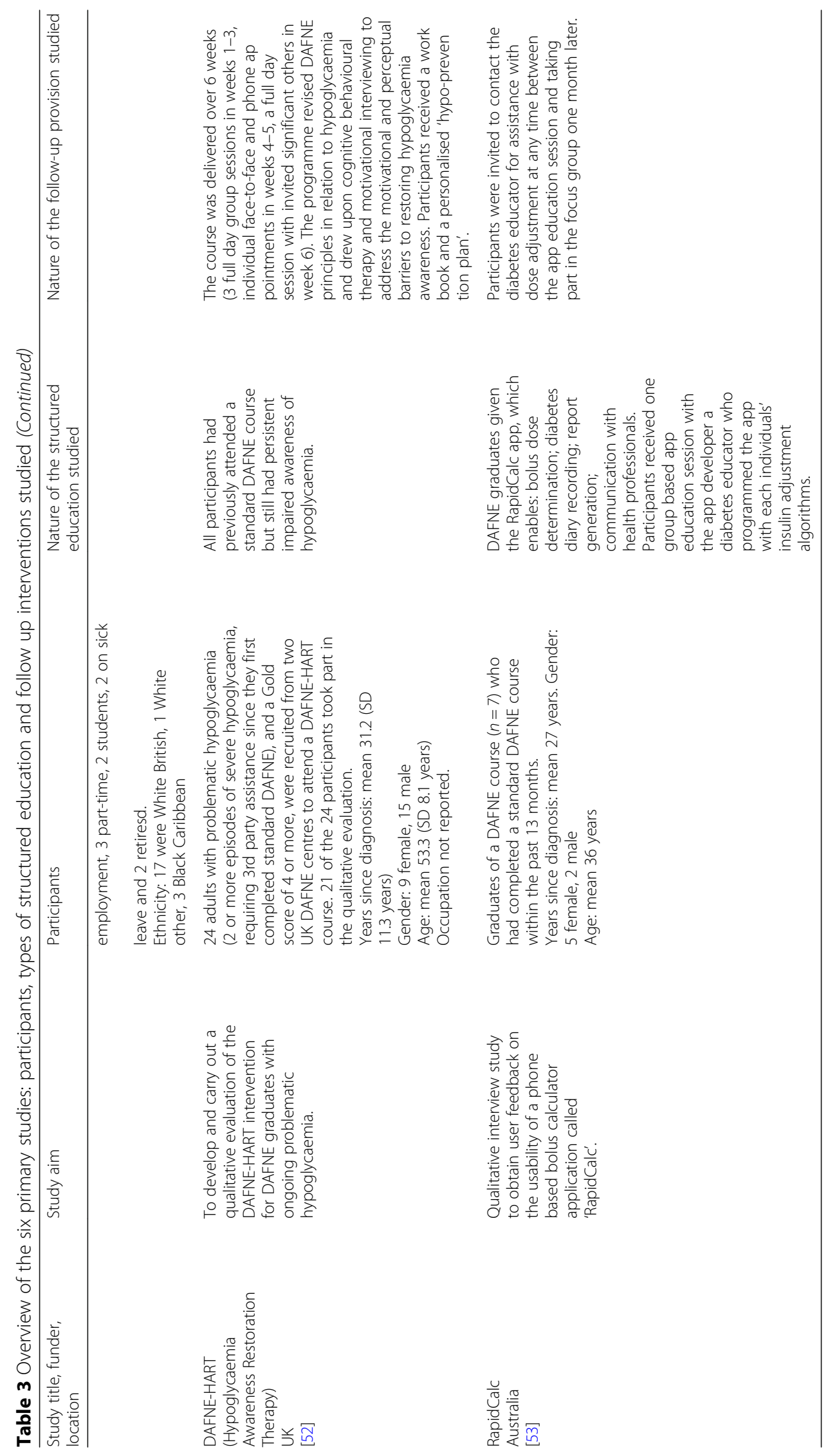




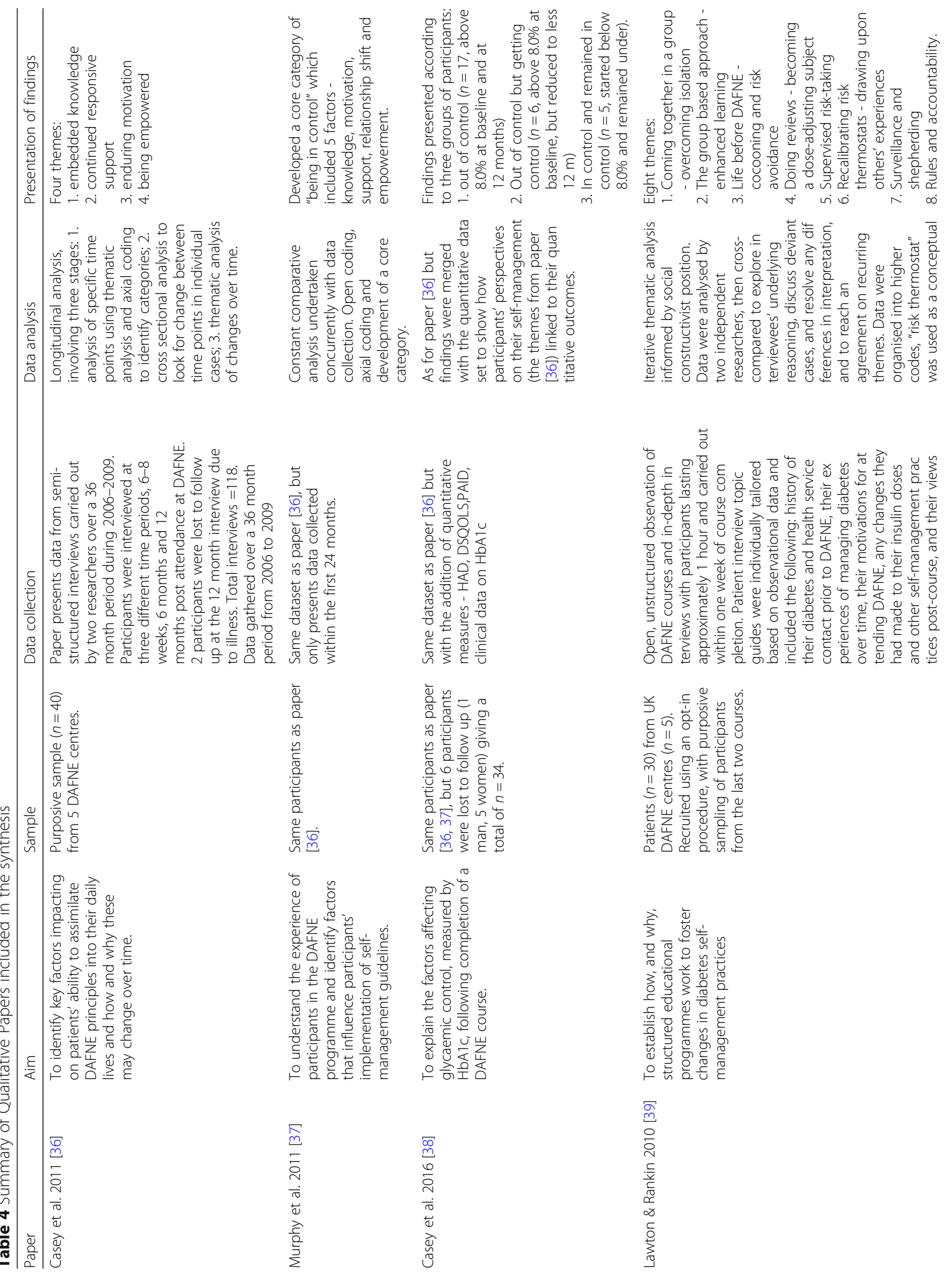




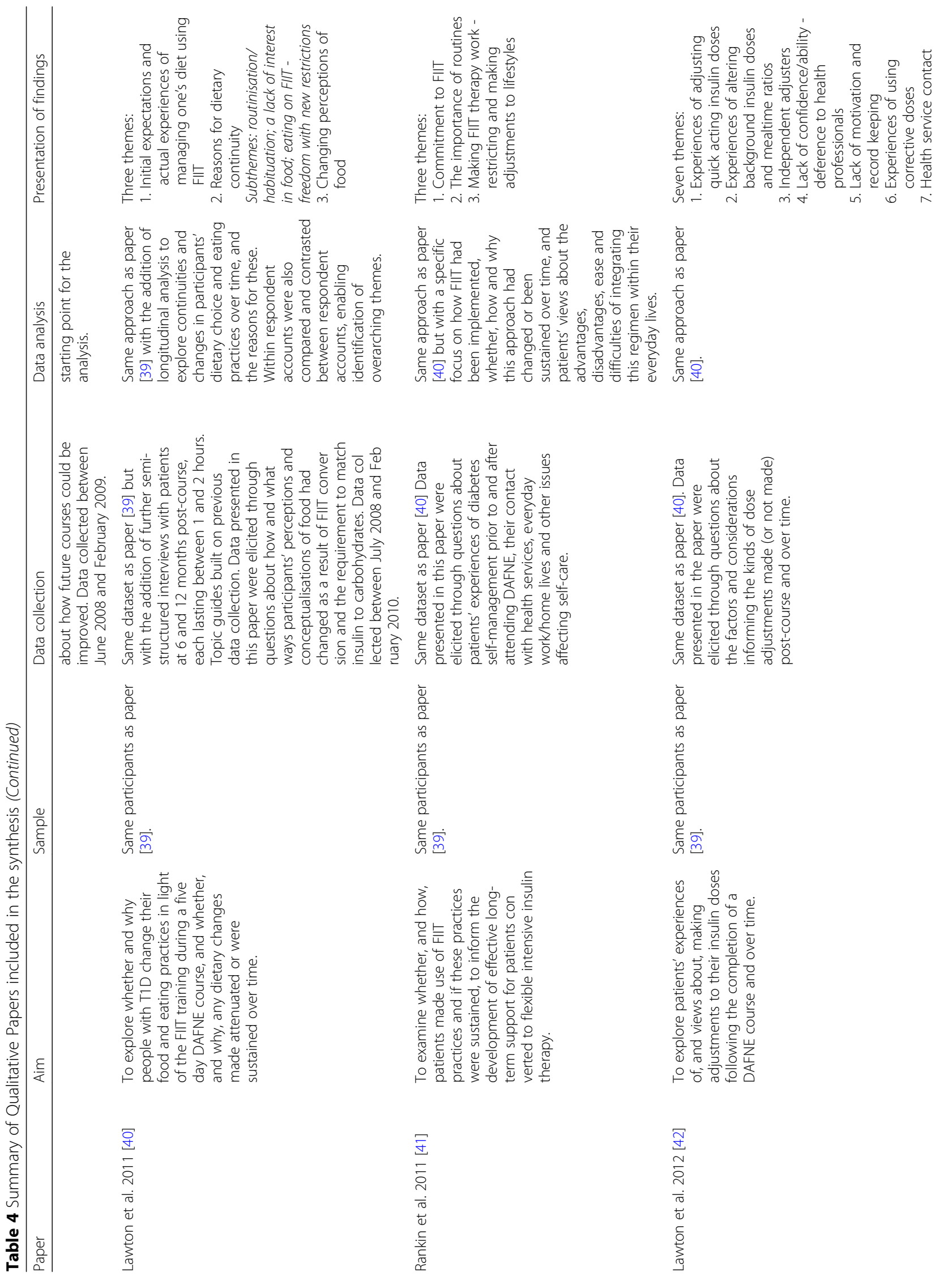




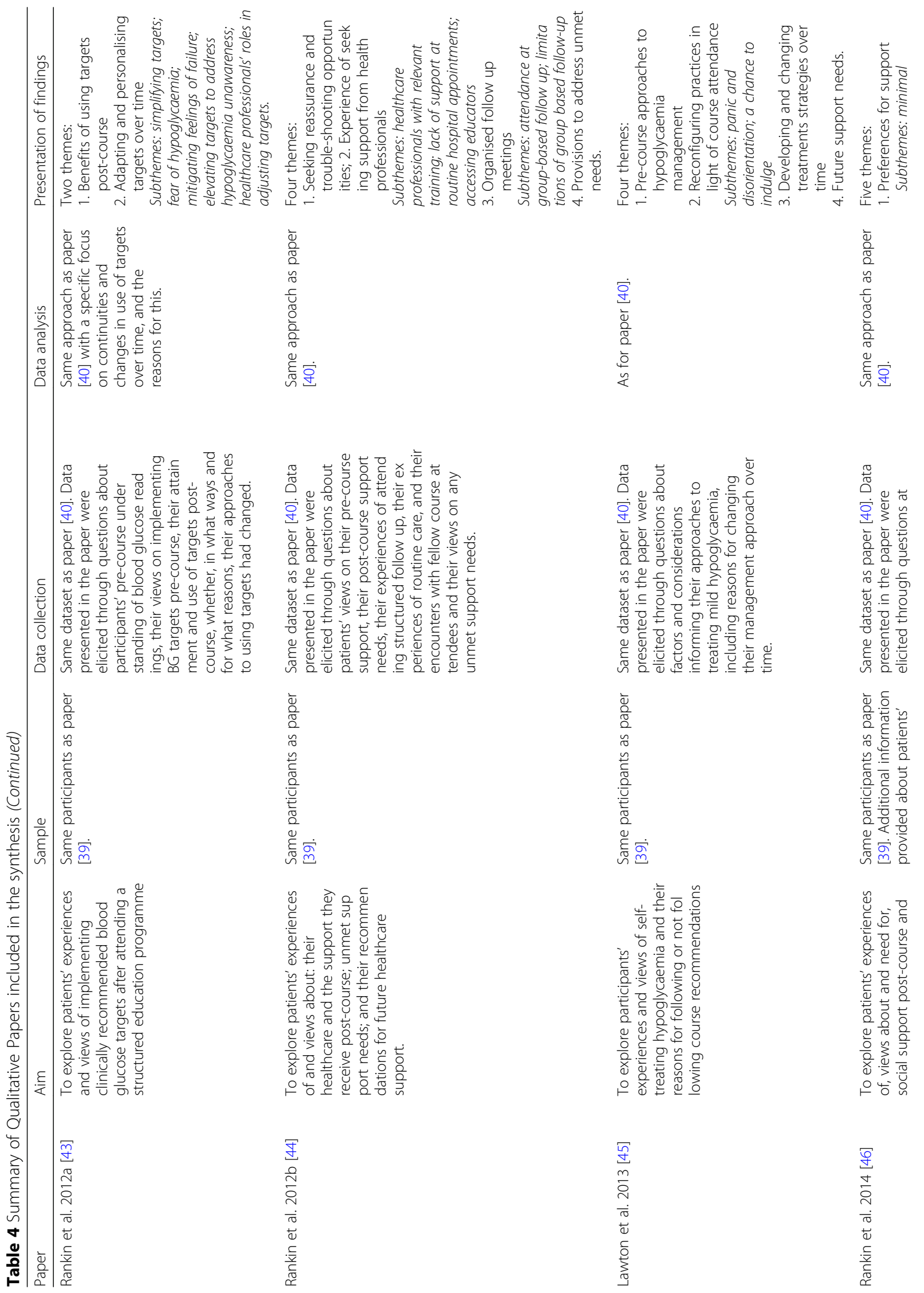




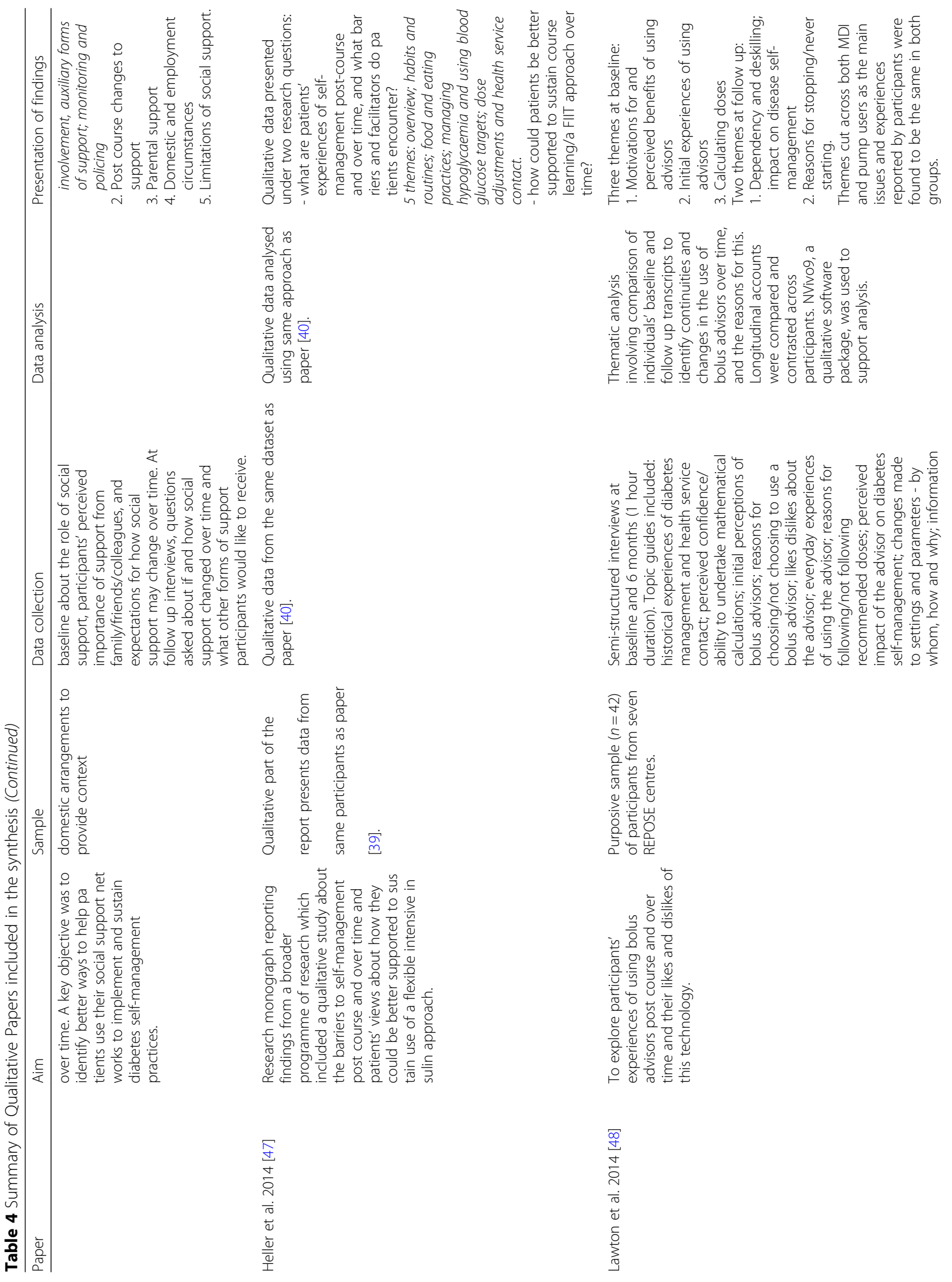




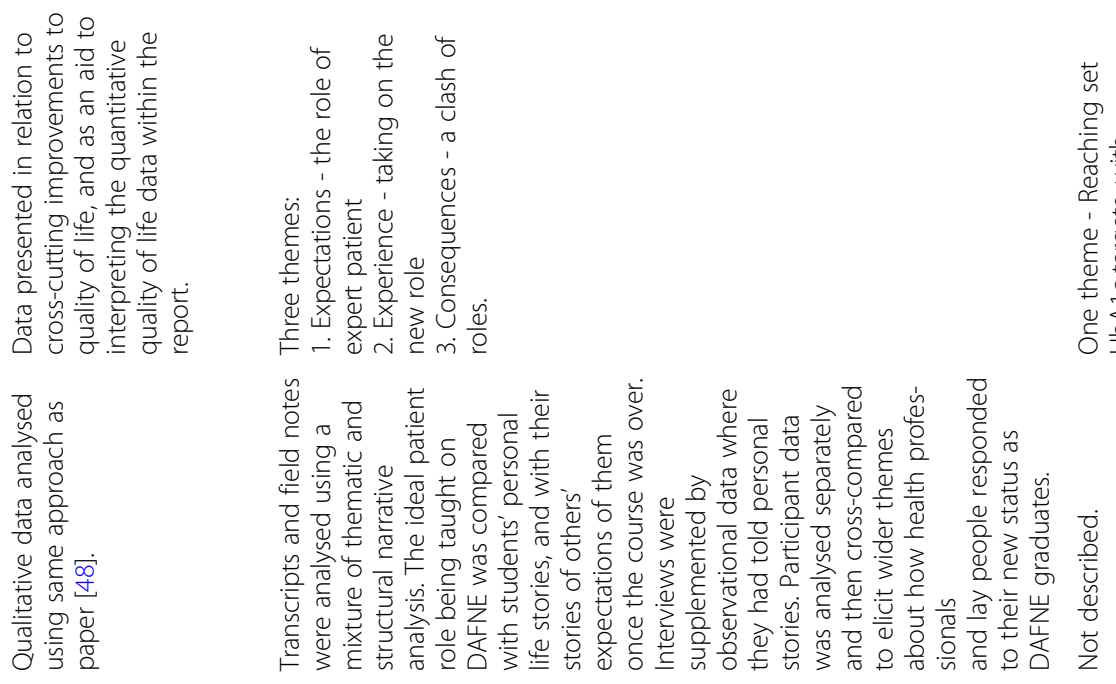

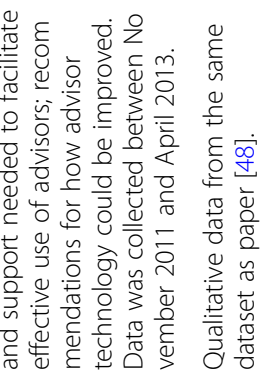
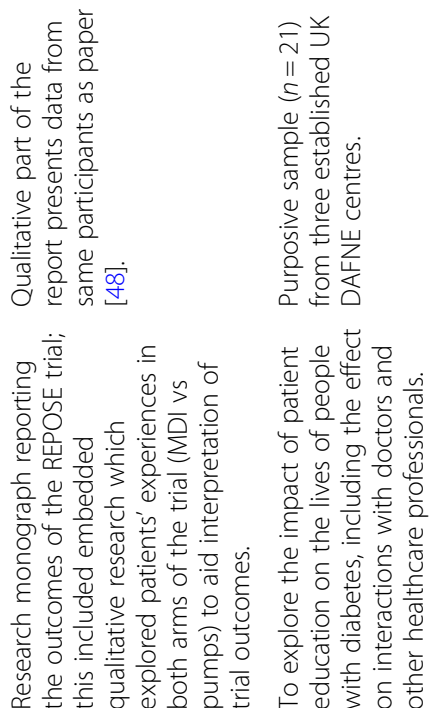

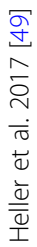

혹

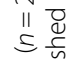

है

它

离岂

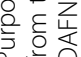

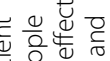

20

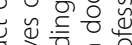

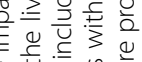

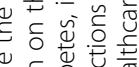

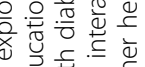

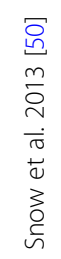

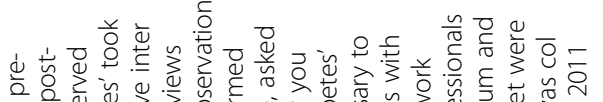

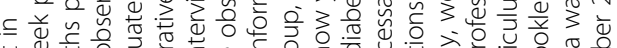

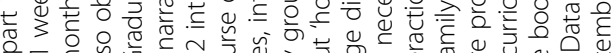

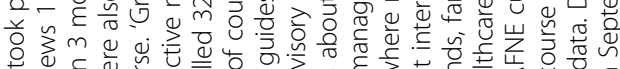

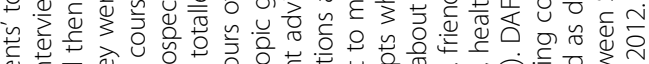
弯.

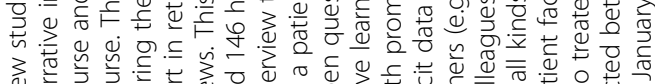

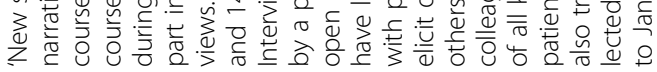

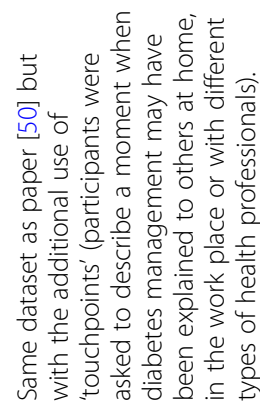

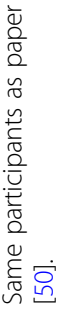

$\subseteq \frac{D_{0}}{\frac{C}{\sigma}}$

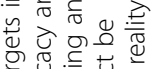

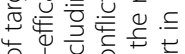

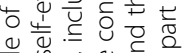

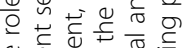

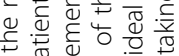

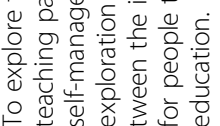

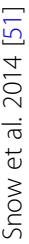




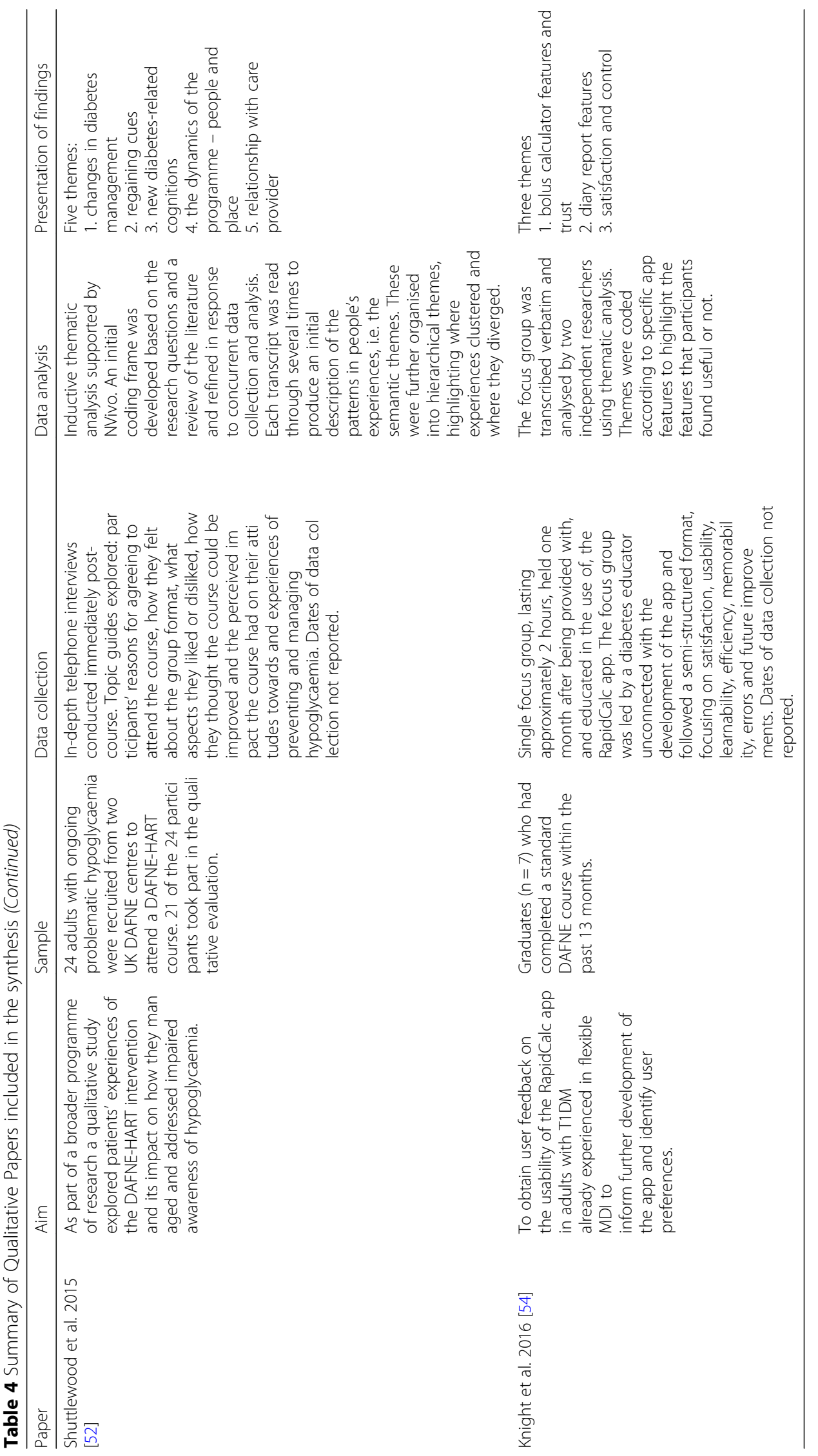


Campbell et al. BMC Health Services Research

(2018) 18:898

Page 15 of 24

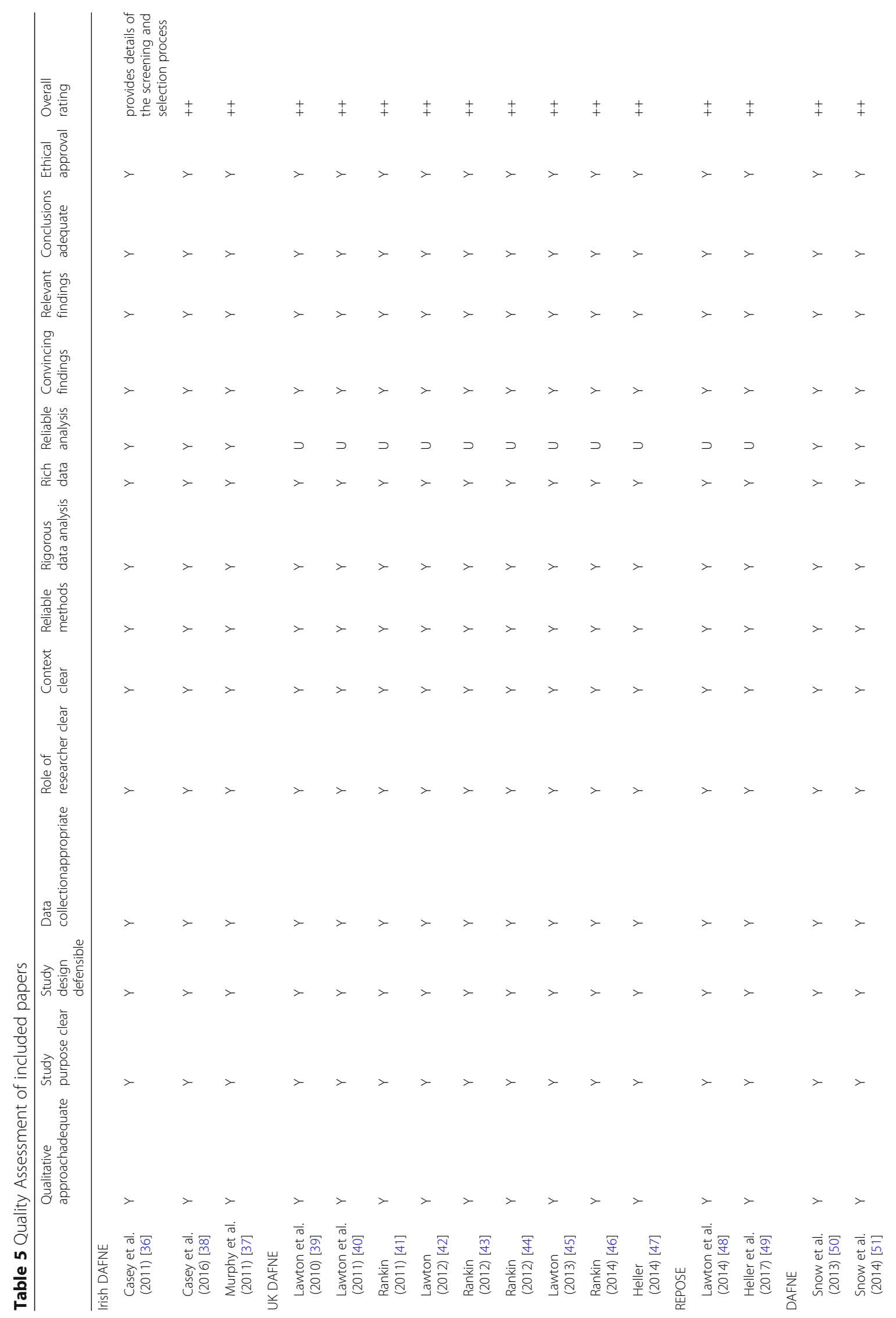




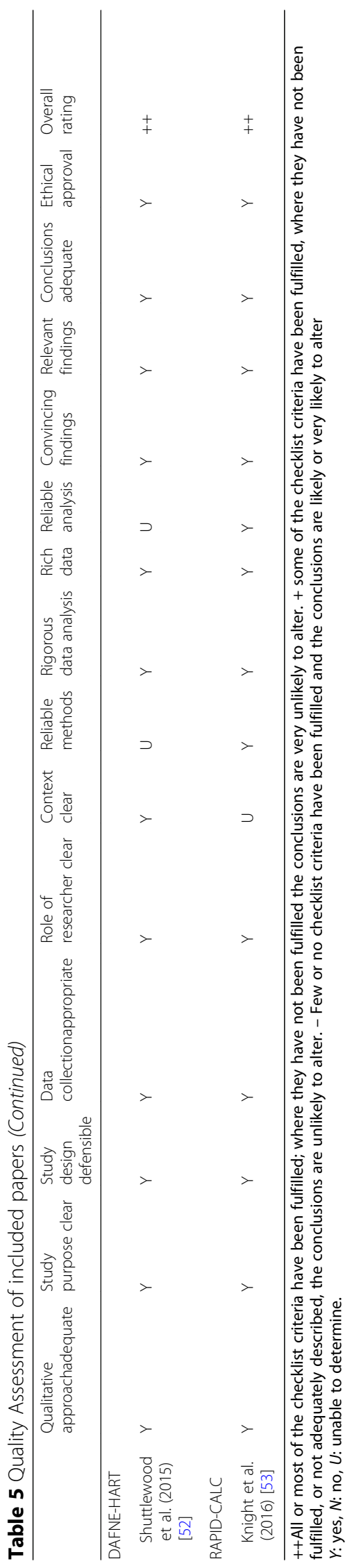




\section{Lack of confidence in their own judgement}

Post-SEP many participants question their ability to review blood glucose readings, interpret patterns and make adjustments to background insulin doses and mealtime ratios [37, 42, 44, 47]. Participants may lack the confidence to calculate mealtime insulin doses [48] and be reluctant to change 1:1 mealtime insulin ratios as these keep their calculations simple [42, 47]. Although using an automated bolus advisor can help overcome these difficulties, over-reliance on this technology can prevent participants from developing their mathematical skills and taking greater control over self-management [48]. Some participants do have the confidence to over-ride the bolus advisor - for example, when undertaking planned physical activity or when there are technical problems. Some describe double-checking the bolus advisor's recommendations by doing their own manual calculations [48, 53]. Most participants, however, simply trust the advisor without question [53] and many do not have the confidence or skills needed to change the settings independently in the event that their mealtime insulin requirements change [48]. Moreover, even with the assistance of a bolus advisor, many participants still prefer to defer self-management decisions to health professionals [42].

\section{Insufficient support}

While participants often struggle to adjust background insulin doses and mealtime ratios post-course [42, 43], many are reluctant to initiate contact with SEP educators for fear of over-burdening them [36, 44, 47]. Even when participants do initiate contact, educators may not be easily accessible and many wait until their next diabetes review appointment to raise questions [38, 44, 47]. Although participants may have other sources of support, these are not necessarily helpful. Many participants seek support from significant others [49], but friends and family often lack knowledge about diabetes management, leaving participants feeling confused as they attempt to implement new practices [48]. Following structured education, many participants find that they have greater condition-specific expertise than their primary care teams [44, 50]. Participants find it confusing and disheartening when health professionals 'over-rule' their newly acquired expertise, resulting in some avoiding contact with mainstream services altogether $[37,50]$.

\section{B. Participant response to challenges}

As participants attempt to cope with the challenges they face post-SEP they:

\section{Shift blood glucose targets}

Many participants shift their blood glucose targets upwards over time, whether consciously or inadvertently $[38,43,47]$. This may be to make their targets more achievable or because they struggle to remember them, resulting in their re-instating those used pre-course [9]. Fear of hypoglycaemia, especially nocturnal episodes, can lead participants to use elevated targets as a safety net $[38,43,45,47]$. As professional consultations typically focus on HbA1c rather than day-to-day blood glucose readings, participants' misuse of targets may not always be identified and addressed in routine clinical care [47].

\section{Stop or relax self-monitoring practices}

Participants find recording and reflecting on their blood glucose readings burdensome, leading them to stop or relax these monitoring practices over time [38, 42, 47]. Even if participants continue to undertake regular self-monitoring of blood glucose, they may not make time for detailed data recording, reflection and looking for long term trends [42, 47]. Using an automated bolus advisor can reduce the burden of data recording [48, 49] and apps that link the bolus advisor to participants' smartphones may be an even more convenient means of record keeping [53]. However, even when record keeping is easier, participants who use advisors may be less inclined to review blood glucose data than when they record it manually $[48,53]$.

\section{Over-rely on corrective doses}

Most participants find corrective doses easy to calculate and simple to use in addressing high glucose levels [42]. As a result, many come to rely predominantly on corrective doses to achieve target glucose levels rather than reviewing glucose profiles and using these to alter their background insulin doses or mealtime ratios $[42,47]$.

\section{Over-treat hypoglycaemia}

Some participants purposefully over-treat hypoglycaemia because they do not trust the treatment amounts specified on the course [45]. Participants who have had particularly traumatic hypoglycaemia experiences may over-treat as soon as they experience symptoms [47]. The panic, disorientation, lack of concentration and increased hunger during an episode can also lead to over-treatment [45, 47]. A few participants report using hypoglycaemia as an excuse to over-indulge in foods that they enjoy [45]. Moreover, over-treatment can arise when significant others (e.g. family members) feel panicked or lack knowledge of the correct treatment amounts $[45,47]$. Although they are more likely to report better monitoring and treatment practices post-course, many of those with impaired hypoglycaemia awareness still find it difficult to set aside time to focus upon hypoglycaemia cues to improve their awareness [52].

\section{Simplify life}

Rather than being liberated from previous restrictive regimens, some participants instigate new, but similarly 


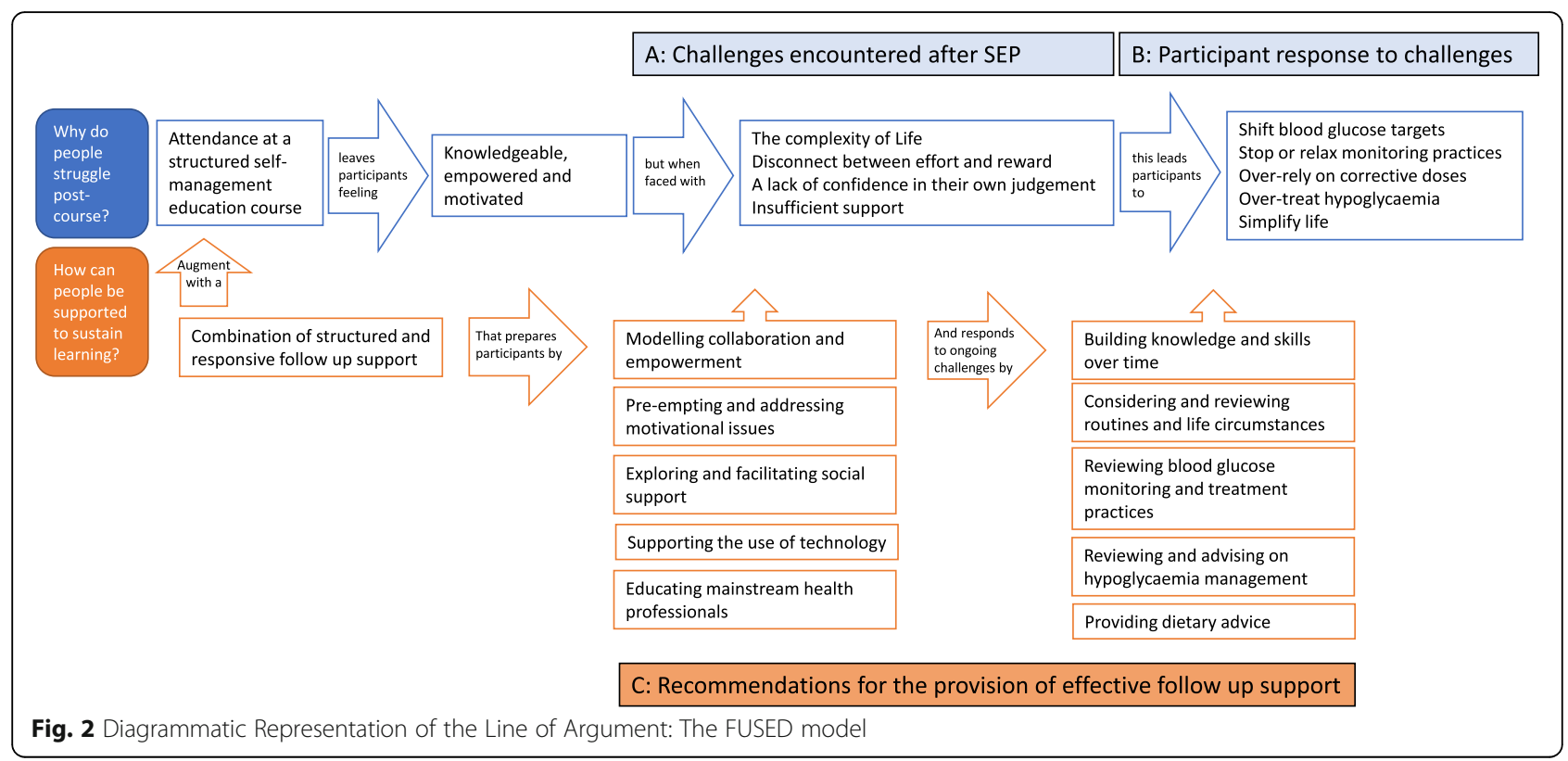

restrictive, practices and routines to help reduce the demands of a FIIT regimen, or increase chances of success [40-42, 47]. These include: regular mealtimes [41, 47]; choosing foods and portion sizes that make carbohydrate counting and mealtime insulin calculations easier and more accurate $[41,47]$; avoiding snacks and, hence, the requirement to administer an insulin injection [40]; eating similar meals every day or ordering the same meal at a restaurant [40, 47]; and avoiding eating out [47]. In addition, participants may also rely on labelled, processed foods to make the determination of carbohydrate content easier $[5,12]$. They may focus on carbohydrate rather than calorific content of foods resulting in inadvertent unhealthy food choices [47].

\section{Recommendations for effective follow-up support}

To sustain effective self-management, participants require a combination of structured and responsive individualised follow-up support $[36,42,44]$. This is recommended for all participants, including those with optimal glycaemic control [36], who have access to good social support [46] and who report confidence in their knowledge and skills [50]. To address participants' reluctance to over-burden health professionals, follow-up support should be fully integrated into the structured education package [44]. In addition to structured follow-up sessions, participants should be provided with opportunities for ad hoc contact with appropriately trained health professionals to troubleshoot problems as they arise and when life circumstances change [42, 44]. Although participants express a preference for receiving support from their own course educators [44, 52], they would also value input from other health professionals, providing they have specialised knowledge of FIIT [36, 42], either in person or via a dedicated phoneline [44, 47]. Although SEPs are effective in a group setting, following the SEP, participants indicate a clear preference for one-to-one, individually tailored follow up support [47]. The FUSED model recommends the following elements as the basis for effective follow-up support:

\section{Modelling collaboration and empowerment}

Follow-up sessions should take a collaborative approach to teaching, learning and problem solving that extends the rationale underpinning programmes by progressively inviting participants to take control, overcome deference to health professionals and bolster confidence in their own capability $[37,42,52]$ to fit diabetes self-management into the complexity and stresses of modern life. For example, reviewing blood glucose data in a follow-up session should not focus solely on improving outcomes, but rather should seek to model the collaborative problem-solving process and use this as an opportunity to develop self-confidence and transform deferential attitudes [39]. The way information is presented and the interpersonal style of the healthcare professional delivering the support is key to promoting personal agency [52].

\section{Preparing for and addressing motivational issues}

Sustaining motivation is crucial if participants are to persist in using recommended self-management practices, particularly the more burdensome tasks such as record keeping [38]. Follow-up support can address motivational issues by pre-warning participants about and acknowledging feelings of disconnect between effort and reward [51] and ensuring ad-hoc support is readily available when 
Table 6 The parts making the whole - contribution of each study and paper to each concept in the line of argument

\begin{tabular}{|c|c|c|c|c|c|c|c|c|c|c|c|c|c|c|c|c|c|c|c|}
\hline & \multirow{2}{*}{$\begin{array}{l}\text { STUDY: } \\
\text { PAPER: }\end{array}$} & \multicolumn{3}{|c|}{ Irish DAFNE } & \multicolumn{9}{|c|}{ UK DAFNE } & \multicolumn{2}{|c|}{ REPOSE } & \multicolumn{2}{|c|}{ DAFNE } & \multirow{2}{*}{$\begin{array}{l}\text { DAFNE-HART } \\
{[52]}\end{array}$} & \multirow{2}{*}{$\begin{array}{l}\text { RAPID } \\
\text { CALC } \\
{[53]} \\
\end{array}$} \\
\hline & & {$[36]$} & [37] & {$[38]$} & [39] & {$[40]$} & [41] & {$[42]$} & [43] & {$[44]$} & {$[45]$} & {$[46]$} & {$[47]$} & {$[48]$} & {$[49]$} & {$[50]$} & {$[51]$} & & \\
\hline \multirow[t]{5}{*}{$\begin{array}{l}\text { A. } \\
\text { Challenges }\end{array}$} & $\begin{array}{l}\text { Knowledgeable } \\
\text { Empowered, } \\
\text { Motivated }\end{array}$ & $x$ & $x$ & $x$ & $x$ & $x$ & $x$ & $x$ & $\mathrm{x}$ & $x$ & $x$ & $x$ & $x$ & & $x$ & $x$ & $x$ & $\mathrm{x}$ & \\
\hline & Complexity of Life & $\mathbf{x}$ & & $\mathbf{x}$ & $x$ & & $x$ & & & & & & $x$ & & & $\mathrm{x}$ & & & \\
\hline & $\begin{array}{l}\text { Disconnect between } \\
\text { effort and reward }\end{array}$ & $x$ & & $\mathbf{x}$ & & $\mathbf{x}$ & & & $\mathbf{x}$ & & & & & & & $x$ & $\mathrm{x}$ & & \\
\hline & $\begin{array}{l}\text { Lack of confidence in } \\
\text { their own judgement }\end{array}$ & & $\mathrm{x}$ & & & & & $x$ & & $\mathbf{x}$ & & & $\mathbf{x}$ & $\mathbf{x}$ & & & & & $x$ \\
\hline & Insufficient Support & $\mathbf{x}$ & $x$ & $\mathbf{x}$ & & & & $\mathbf{x}$ & $x$ & $\mathbf{x}$ & & $\mathbf{x}$ & $x$ & & $\mathbf{x}$ & $\mathrm{x}$ & & & \\
\hline \multirow[t]{5}{*}{$\begin{array}{l}\text { B. Participant } \\
\text { response }\end{array}$} & $\begin{array}{l}\text { Shift blood } \\
\text { glucose targets }\end{array}$ & & & $\mathbf{x}$ & & & & & $\mathbf{x}$ & $\mathbf{x}$ & $\mathrm{x}$ & & $x$ & & & & & & \\
\hline & $\begin{array}{l}\text { Stop or relax self- } \\
\text { monitoring practices }\end{array}$ & & & $x$ & & & & $\mathbf{x}$ & & & & & $\mathbf{x}$ & $x$ & $x$ & & & & $\mathbf{x}$ \\
\hline & $\begin{array}{l}\text { Over-rely on } \\
\text { corrective doses }\end{array}$ & & & & & & & $x$ & & & & & $\mathbf{x}$ & & & & & & \\
\hline & $\begin{array}{l}\text { Over-treat } \\
\text { hypoglycaemia }\end{array}$ & & & & & & & & & & $x$ & & $\mathbf{x}$ & & & & & $\mathrm{x}$ & \\
\hline & Simplify Life & & & & & $\mathbf{x}$ & $\mathbf{x}$ & $\mathbf{x}$ & & & & & $x$ & & & & & & \\
\hline \multirow[t]{11}{*}{ C. Follow-up } & $\begin{array}{l}\text { A combination } \\
\text { of structured and } \\
\text { responsive } \\
\text { individual support }\end{array}$ & $\mathrm{x}$ & & & & & & $x$ & & $x$ & & $x$ & $\mathbf{x}$ & & & $\mathbf{x}$ & & $x$ & \\
\hline & $\begin{array}{l}\text { Modelling collaboration } \\
\text { and empowerment }\end{array}$ & & $x$ & & $\mathbf{x}$ & & & $x$ & & & & & & & & & & $x$ & \\
\hline & $\begin{array}{l}\text { Preparing for and } \\
\text { addressing } \\
\text { motivational issues }\end{array}$ & $\mathbf{x}$ & & $x$ & & & & & & & $x$ & & $x$ & & & & $x$ & $x$ & \\
\hline & $\begin{array}{l}\text { Exploring and } \\
\text { facilitating social } \\
\text { support }\end{array}$ & & & & & $x$ & & & & & $x$ & $x$ & $x$ & & & & & & \\
\hline & $\begin{array}{l}\text { Supporting the } \\
\text { use of technology }\end{array}$ & & & & & & & $x$ & & & & & & $x$ & & & & & $x$ \\
\hline & $\begin{array}{l}\text { Educating mainstream } \\
\text { health professionals }\end{array}$ & & & & & & & & & $\mathbf{x}$ & & & $\mathbf{x}$ & & & $\mathbf{x}$ & & & \\
\hline & $\begin{array}{l}\text { Building knowledge } \\
\text { over time }\end{array}$ & $\mathbf{x}$ & & & & & & $\mathbf{x}$ & & & & & $\mathbf{x}$ & & & & & & \\
\hline & $\begin{array}{l}\text { Considering and } \\
\text { revising routines and } \\
\text { life circumstances }\end{array}$ & & & & & & $x$ & & & & & & & & & & & & \\
\hline & $\begin{array}{l}\text { Reviewing and } \\
\text { revising blood glucose } \\
\text { monitoring and } \\
\text { treatment practices }\end{array}$ & & & $\mathbf{x}$ & & & & $\mathbf{x}$ & $x$ & & & & & & & & & & \\
\hline & $\begin{array}{l}\text { Reviewing and advising } \\
\text { on hypoglycaemia } \\
\text { management }\end{array}$ & & & & & & & & $x$ & & $x$ & & & & & & & & $\mathbf{x}$ \\
\hline & $\begin{array}{l}\text { Providing } \\
\text { dietary advice }\end{array}$ & & & & & $\mathbf{x}$ & & & & & & & & & & & & & \\
\hline
\end{tabular}

needed [38]. Cognitive behavioural theory, motivational interviewing [52] and behaviour change theories [47] could also be used to inform the design of follow-up support to help promote sustained use of self-management practices. Course educators may benefit from additional psychological skills training [52] and could consider referring participants to specialist mental health input where appropriate $[36,45]$. 


\section{Exploring and facilitating social support}

Asking participants about the level of support they receive from significant others (family, friends and work colleagues), how this helps or hinders self-management, and how they might draw upon social support in the future, can inform discussions and advice about how to effectively utilise social support $[45,46]$. It may be appropriate to invite family members to attend specific follow-up sessions, for example on carbohydrate counting [47] or treating hypoglycaemia [46], or provide information and training geared specifically towards significant others [40, 45]. Any exploration of social support should be sensitive to participants' preferences and the involvement of significant others should only be pursued if they think this would be helpful [46].

\section{Supporting the use of technology}

For participants who struggle to record, review and interpret their blood glucose readings, the development and use of technology, such as online diaries, apps or downloadable glucose meters, could make some self-management practices easier [42, 53]. Use of automated bolus advisors should be reviewed regularly at follow-up to ensure: the device is programmed with the correct parameters; participants understand how and when to change settings; and they continue to access and review their blood glucose data $[48,53]$. If participants do not do this, follow up sessions could explore why and work with them to make more effective use of the technology [48]. Moreover, future technological advancements such as developing a bolus advisor or app that shows how the dose was calculated on screen might provide an important learning opportunity [53].

\section{Educating mainstream health professionals}

Dedicated follow-up support can prevent and counteract difficult interactions with non-specialist health professionals in mainstream services by being the first port of call for FIIT specific advice [44], providing training for participants in assertiveness skills, and writing letters to participants' mainstream health professionals explaining the FIIT approach [50]. It is also crucial that all general health professionals are educated about self-management principles and how to develop collaborative working practices $[47,50]$.

\section{Building knowledge and skills over time}

Follow-up support provides an opportunity to review knowledge and skills post-course, highlight individual difficulties, revise knowledge and address skills gaps [36, 42, 47]. As well as helping to sustain knowledge and skills, follow-up support can build on and update participants' knowledge in the months and years after course completion, for example by keeping them informed about new advances in knowledge [47]. This could involve providing information directly as part of follow-up sessions, or signposting to useful resources.

\section{Considering and revising routines and life circumstances}

Follow-up support should explore whether, and how, participants' life circumstances, eating patterns and routines have changed post-course [41]. Participants could be advised to implement structured routines in the first instance, and then be supported to become progressively more flexible as they develop confidence and consolidate their self-management skills [41]. Highly routinized lifestyles are potentially detrimental to quality of life and could compromise participants' motivation to sustain self-management principles; hence, participants should be encouraged to reflect on their satisfaction with routines [41].

\section{Reviewing and revising blood glucose monitoring and treatment practices}

Follow-up sessions should incorporate a review of blood glucose readings and support participants to consolidate their skills in identifying and interpreting patterns and responding with appropriate regimen changes [42]. It is important to reinforce the importance of record keeping in addition to regular blood glucose checking [38, 42], encourage participants to use clinically-recommended blood glucose target ranges, and help identify and address barriers to their use $[42,43]$.

\section{Reviewing and advising on hypoglycaemia management}

Follow-up support should review how participants are treating hypoglycaemia, identify whether they are over-treating and provide further education and advice where required [43, 45, 52]. Health professionals should review treatment of hypoglycaemia for all participants and not only those with identified impaired awareness of hypoglycaemia [43]. Follow-up support should explore with participants: their frequency of severe hypoglycaemic episodes; the blood glucose level they identify as 'low'; and how often they have been prompted by significant others to treat hypoglycaemia [45]. Given that night-time targets are most likely to be adjusted upwards, follow-up support should include a conversation about attitudes towards nocturnal hypoglycaemia [43].

\section{Providing dietary advice}

During follow-up, facilitators need to establish if and what changes in food and eating practices have occurred as a result of attending the SEP to ensure that advice and support is correctly tailored. Follow-up sessions should: explore whether participants are restricting their food choices; identify those struggling with carbohydrate counting; explore if participants are relying more heavily on processed foods to aid carbohydrate counting and 
monitor their weight accordingly. Involving family or friends who influence food choices and preparation in the follow-up session, providing information to assist with knowing the carbohydrate and calorie content of foods, and appropriate referral to a dietician may be useful elements of a tailored approach for follow-up support [40].

\section{Discussion}

Participation in a SEP, based on a FIIT approach, empowers individuals by providing them with the skills and competencies needed to undertake effective diabetes self-management. However, while participants who have attended a SEP often gain initial clinical benefit, typically evidenced by an improved HbA1c or a reduction in severe hypoglycaemic episodes, many encounter difficulties maintaining the skills and competencies taught on their courses over time. This is a pattern frequently shown in evaluations of self-management programmes, where benefits can be short-lived, and may attenuate substantially six months to a year after a programme ends $[54,55]$. In this paper, which synthesises the available qualitative evidence about participants' experiences of undertaking diabetes self-management after attending a SEP for people with T1DM, we add strength to the argument that skills training alone does not necessarily lead to individuals sustaining desired changes in behaviour. The FUSED model provides a framework for understanding why participants can struggle to maintain their learning and skills post-SEP attendance and, crucially, explicates how these barriers can be addressed through the provision of timely, tailored follow-up support.

The need for ongoing support for effective self-management following SEP is recognised not only for people with T1DM but also those with T2DM and other chronic health conditions [56-58]. While there is agreement that support needs to be ongoing and individualised, the actual features and components of such support and how it should be delivered are less well described. The FUSED model addresses this gap by outlining ten tangible recommendations for service delivery and acting as a logic model which can be used to underpin the design of follow-up support. Although developed in the context of T1DM, the model may also offer insights applicable to supporting self-management of other long-term chronic such as T2DM, asthma, cystic fibrosis.

The FUSED model calls for a more resource intensive and responsive approach which clearly may be more costly in the short-term than current approaches delivered as part of routine clinical care (e.g. annual/bi-annual diabetes review appointments). However, it may ultimately enable cost savings if it proves more clinically effective; for example, it may result in less patients progressing to requiring insulin pump therapy, and/or experiencing less diabetes-related microvascular complications. Before implementing such change in approach, it will be necessary to convince diabetes professionals of the potential benefits. Since many diabetes nurse specialists spend much of their time in repeated 1:1 consultations with individuals who are struggling to manage their diabetes successfully, which rarely leads to improved outcomes, they may be willing to explore different tactics. The multi-disciplinary team will also require additional training to deliver this new approach and finding trainers with the required skills and attitudes may be challenging. Hence, future work will be needed to establish the feasibility, acceptability and cost-effectiveness of a FUSED approach.

In addition, the model highlights the potential for technological support to sustain skills via online learning and enhanced monitoring. Existing research shows that technological support is likely to be most effective when it connects people with T1DM to their health care team using 2-way communication, where it analyses patient-generated health data, and provides tailored education and individualized feedback between a person with diabetes and their health care team [59]. As technology advances, it is crucial that future research explores how it can be successfully integrated within follow up support after SEP attendance to most effectively and efficiently provide the right support at the right time.

\section{What next?}

We are using the FUSED model to inform the design of the follow-up support which will be delivered as part of a complex intervention called 'DAFNEplus'. DAFNEplus is a structured education programme for people with T1DM, which, in addition to using a FUSED approach to follow-up support, comprises an adapted DAFNE course, embedding behaviour change/maintenance principles, and technological support. (https://dafneplusresearch.wordpress.com/).

DAFNEplus is currently being piloted in three sites prior to a definitive randomised controlled trial. The trial will include an economic and mixed-methods process evaluation which will allow us to explore how the FUSED model works in practice and evaluate this new approach to follow-up support. As well as looking at clinical and cost effectiveness, a key part of the research process will be to explore the acceptability of the FUSED follow-up model from both health professionals' and participants' perspectives. We will also determine how readily this new approach to follow-up support may be adopted into mainstream diabetes care.

\section{Strengths and weaknesses}

Most of the papers included in the synthesis were of high quality and most reported longitudinal data 
collected at several time points up to a year following SEP attendance [36-47] with other papers reporting data from participants who had attended up to 11 years previously [50, 51]. The gaps and support requirements highlighted in the FUSED model are therefore supported by rich, long-term insights. When considering the potential limitations of this review, it should be borne in mind that the included papers explored the experiences of individuals who had attended the DAFNE programme in the UK and Southern Ireland. Hence, some recommendations may be less applicable in other countries where health care is funded and delivered differently and where other approaches to structured education are used. A further limitation is that, although the review draws on data from eighteen publications, these report from only six separate studies. There were also some limitations in the review process, with only one reviewer screening search results, and limited checking of data extraction raising the risk of error in identification of relevant studies and data. However, the involvement of four authors, who also were authors in 13 of the primary studies allowed interpretations of the data to be verified. To maintain rigor, these authors did not participate in quality appraisal of the included studies.

\section{Conclusion}

In summary, our recommendation is that structured education should no longer be a discrete intervention, but, rather, an on-going programme involving a potentially life-long package of tailored and individualised follow-up support, which also uses technology to facilitate and support those close communications with specialist health professionals and builds self-efficacy to confidently maintain self-management. Using a meta-ethnographic approach to a systematic review of the qualitative literature of people's long-term experiences of self-management in T1DM, we have developed the FUSED model to guide the development of follow-up support for adults with T1DM. The model can contribute to the redesign of patient-centred health services, HCP training, and availability of technology. It may also provide insights for other conditions, which also rely on long-term self-management.

\section{Additional files}

Additional file 1: Sample search strategy. (PDF $95 \mathrm{~kb})$

Additional file 2: List of excluded studies. (PDF $42 \mathrm{~kb}$ )

\section{Abbreviations}

BME: Black and minority ethnic; DAFNE: Dose Adjustment for Normal Eating; DAFNE-HART: DAFNE + Hypoglycaemia Awareness Restoration Therapy; DTTP: Düsseldorf, the Diabetes Treatment and Teaching Programme; FIIT: Flexible intensive insulin therapy; FUSED: Follow-Up Support for Effective type 1 Diabetes self-management; HbA1c: Glycated haemoglobin; REPOSE: Relative Effectiveness of Pumps Over MDI and Structured Education;
SEPs: Structured education programmes; T1DM: Type 1 diabetes mellitus; T2DM: Type 2 diabetes mellitus

\section{Acknowledgements}

Not applicable.

\section{Funding}

The research received funding from the National Institute for Health Research Programme Grants for Applied Research (RP-PG-0514-20013) awarded to Professor Simon Heller. The funding body had no role in the design of the review, identification of studies, analysis and interpretation of data or in the writing of the manuscript.

\section{Availability of data and materials}

The primary studies included in this qualitative synthesis are publicly available.

\section{Author's contributions}

FC \& SH were responsible for the initial review conception and design, FC and JPB developed the review protocol. MC developed the search strategies and undertook electronic databases searches. FC screened the results, FC and JPB extracted data. FC took a lead role in an initial rapid analysis. JPB took a lead role in the higher level analysis which led to the development of the FUSED model. FC \& JPB made substantial contributions to drafting the manuscript. JL, $\mathrm{DR}, \mathrm{EC}, \mathrm{NdeZ}, \mathrm{JE} \& \mathrm{SH}$ contributed to writing the introduction and discussion. FC, JL, DR, EC, NdeZ, JE, SH all reviewed and revised the manuscript in preparation for submission. All authors read and approved the final manuscript.

\section{Ethics approval and consent to participate}

Not applicable.

\section{Consent for publication}

Not applicable.

\section{Competing interests}

Nicole de Zoysa declares that an Honorarium was paid to her employer by Eli Lilly for educational lecture (Nov 2014). The other authors declare that they have no competing interes

\section{Publisher's Note}

Springer Nature remains neutral with regard to jurisdictional claims in published maps and institutional affiliations.

\section{Author details}

${ }^{1}$ School of Health and Related Research (ScHARR), University of Sheffield, Regent Court, 30 Regent Street, S1 4DA Sheffield, England. ${ }^{2}$ The Usher Institute of Population Health Sciences and Informatics, Edinburgh Medical School of Molecular, Genetic and Population Health Sciences, University of Edinburgh, Teviot Place, Edinburgh EH8 9AG, Scotland. ${ }^{3}$ Diabetes Centre, King's College Hospital, Denmark Hill, London SE5 9RS, England. ${ }^{4}$ Sheffield University School of Medicine, Academic Unit of Diabetes, Endocrinology, and Metabolism, School of Medicine and Biomedical Sciences, Sheffield, UK. ${ }^{5}$ School of Nursing and Health Sciences, University of Dundee, 11 Airlie Place, Dundee DD1 4HJ, Scotland.

Received: 26 February 2018 Accepted: 26 October 2018 Published online: 27 November 2018

\section{References}

1. American Diabetes Association. Diagnosis and Classification of Diabetes Mellitus. Diabetes Care. 2004;27(suppl 1):s5-s10.

2. Patterson CC, et al. Trends in childhood type 1 diabetes incidence in Europe during 1989-2008: evidence of non-uniformity over time in rates of increase. Diabetologia. 2012;55(8):2142-7.

3. Daneman D. Type 1 diabetes. Lancet. 2006;367(9513):847-58.

4. Soedamah-Muthu SS, et al. All-cause mortality rates in patients with type 1 diabetes mellitus compared with a non-diabetic population from the UK general practice research database, 1992-1999. Diabetologia. 2006;49(4):660-6.

5. Secrest, A.M., et al., All-Cause Mortality Trends in a Large Population-Based Cohort With Long-Standing Childhood-Onset Type 1 Diabetes. The Allegheny County Type 1 Diabetes Registry, Diabetes Care. 2010. 33(12): p. 2573-2579. 
6. Haas $L$, et al. National Standards for diabetes self-management education and support. Diabetes Educ. 2012;38(5):619-29.

7. Norris, S.L., et al., Self-Management Education for Adults With Type 2 Diabetes. A meta-analysis of the effect on glycemic control, 2002. 25(7): p. 1159-1171.

8. Funnell MM, et al. National Standards for diabetes self-management education. Diabetes Care. 2009;32(Supplement 1):S87-94.

9. Franc $S$, et al. Real-life application and validation of flexible intensive insulintherapy algorithms in type 1 diabetes patients. Diabetes Metab. 2009;35(6): 463-8.

10. Mühlhauser I, et al. Evaluation of an intensified insulin treatment and teaching programme as routine management of type 1 (insulin-dependent) diabetes. Diabetologia. 1987;30(9):681-90.

11. Mühlhauser I, et al. Bicentric evaluation of a teaching and treatment programme for type 1 (insulin-dependent) diabetic patients: improvement of metabolic control and other measures of diabetes care for up to 22 months. Diabetologia. 1983;25(6):470-6.

12. McIntyre HD. DAFNE (dose adjustment for Normal eating): structured education in insulin replacement therapy for type 1 diabetes. Med J Aust. 2006;184(7):317-8

13. Group, D.S. Training in flexible, intensive insulin management to enable dietary freedom in people with type 1 diabetes: dose adjustment for normal eating (DAFNE) randomised controlled trial. BMJ. 2002;325(7367):746.

14. Heller SR. Structured education in type 1 diabetes. The British Journal of Diabetes \& Vascular Disease. 2009;9(6):269-72.

15. National Clinical Guideline, C., National Institute for Health and Care Excellence. Clinical Guidelines, in Type 1 Diabetes in Adults: Diagnosis and Management. London: National Institute for Health and Care Excellence (UK; 2015.

16. Lowe J, et al. Flexible eating and flexible insulin dosing in patients with diabetes: results of an intensive self-management course. Diabetes Res Clin Pract. 2008;80(3):439-43.

17. Pieber TR, et al. Evaluation of a structured outpatient group education program for intensive insulin therapy. Diabetes Care. 1995;18(5):625-30.

18. Plank J, et al. Long-term evaluation of a structured outpatient education programme for intensified insulin therapy in patients with type 1 diabetes: a 12-year follow-up. Diabetologia. 2004;47(8):1370-5.

19. Mclntyre HD, et al. Dose adjustment for normal eating (DAFNE) - an audit of outcomes in Australia. Med J Aust. 2010;192(11):637-40.

20. Gunn D, Mansell P. Glycaemic control and weight 7 years after dose adjustment for Normal eating (DAFNE) structured education in type 1 diabetes. Diabet Med. 2012;29(6):807-12.

21. Speight J, et al. Long-term biomedical and psychosocial outcomes following DAFNE (dose adjustment for Normal eating) structured education to promote intensive insulin therapy in adults with sub-optimally controlled type 1 diabetes. Diabetes Res Clin Pract. 2010;89(1):22-9.

22. Bott $\mathrm{S}$, et al. Intensified insulin therapy and the risk of severe hypoglycaemia. Diabetologia. 1997;40(8):926-32.

23. Hopkins D, et al. Improved biomedical and psychological outcomes 1 year after structured education in flexible insulin therapy for people with type 1 diabetes: the U.K. DAFNE experience. Diabetes Care. 2012; 35(8):1638-42.

24. Heller, S.L., Lawton J; Amiel S; Cooke D., Mansell P., Brennan A., Elliott J. , Boote J., Emery C., Baird W., Basarir H., Beveridge S., Bond R., Campbell M., Chater T., Choudhary P., Clark M., de Zoysa N., Dixon S., Gianfrancesco C., Hopkins D., Hacques R., Kruger J., Moore S., Oliver L., Peasgood T., Rankin D., Roberts S., Rogers H., Taylor C., Thokala P., Thompson G., Ward C., Improving management of type 1 diabetes in teh UK: the Dose Adjustment For Normal Eating (DAFNE) programme as a research test-bed. A mixed metod analysis of the barriers to and facilitators of successful diabetes self-management, a health conomic analysis, a cluster randomised controlled trial of different models of delivery of an educational intervention and the pottential of insulin pubmps and additiaonal educator input to improve outcomes. NIHR PGFAR (ref: RP-PG-0514-20013). Programme Grants Appl Res, 2014. 2(5).

25. Noblit GW, Hare RD. Meta-ethnography: synthesizing qualitative studies. Newbury Park: Sage; 1988.

26. Malpass A, et al. "Medication career" or "moral career"? The two sides of managing antidepressants: a meta-ethnography of patients' experience of antidepressants. Soc Sci Med. 2009;68(1):154-68.

27. Campbell $R$, et al. Evaluating meta ethnography: systematic analysis and synthesis of qualitative research. Health Technol Assess. 2012;15(43):1-164.
28. Toye F, et al. Meta-ethnography 25 years on: challenges and insights for synthesising a large number of qualitative studies. BMC Med Res Methodol. 2014;14(1):80.

29. Cooke A, Smith D, Booth A. Beyond PICO: the SPIDER tool for qualitative evidence synthesis. Qual Health Res. 2012;22(10):1435-43.

30. Wong SS-L, Wilczynski NL, Haynes RB. Developing optimal search strategies for detecting clinically relevant qualitative. Medinfo. 2004;107:311.

31. Project, e. Meta-ethnography Reporting Guidance. 2018 2018; Available from: http://emergeproject.org/.

32. Atkins $S$, et al. Conducting a meta-ethnography of qualitative literature: lessons learnt. BMC Med Res Methodol. 2008;8(1):21.

33. Britten $\mathrm{N}$, et al. Using meta ethnography to synthesise qualitative research: a worked example. J. Health Serv. Res. Policy. 2002;7(4):209-15.

34. NICE. Methods for the development of NICE public health guidance. third ed; 2012.

35. Campbell R, et al. Evaluating meta-ethnography: a synthesis of qualitative research on lay experiences of diabetes and diabetes care. Soc Sci Med. 2003;56(4):671-84.

36. Casey $D$, et al. A longitudinal qualitative study examining the factors impacting on the ability of persons with T1DM to assimilate the dose adjustment for Normal eating (DAFNE) principles into daily living and how these factors change over time. BMC Public Health. 2011;11(1):672.

37. Murphy $\mathrm{K}$, et al. Participants' perceptions of the factors that influence diabetes self-management following a structured education (DAFNE) programme. J Clin Nurs. 2011;20(9-10):1282-92.

38. Casey $D$, et al. A mixed methods study exploring the factors and behaviors that affect glycemic control following a structured education program. J Mixed Methods Res. 2016;10(2):182-203.

39. Lawton J, Rankin D. How do structured education programmes work? An ethnographic investigation of the dose adjustment for normal eating (DAFNE) programme for type 1 diabetes patients in the UK. Soc Sci Med. 2010;71(3):486-93.

40. Lawton J, et al. Dose adjustment for Normal eating: a qualitative longitudinal exploration of the food and eating practices of type 1 diabetes patients converted to flexible intensive insulin therapy in the UK. Diabetes Res Clin Pract. 2011;91(1):87-93.

41. Rankin D, et al. How and why do patients with Type 1 diabetes sustain their use of flexible intensive insulin therapy? A qualitative longitudinal investigation of patients' self-management practices following attendance at a Dose Adjustment for Normal Eating (DAFNE) course. Diabet. Med. 2011; 28(5):532-8

42. Lawton J, et al. Patients' experiences of adjusting insulin doses when implementing flexible intensive insulin therapy: a longitudinal, qualitative investigation. Diabetes Res Clin Pract. 2012;98(2):236-42.

43. Rankin D, et al. Experiences of using blood glucose targets when following an intensive insulin regimen: a qualitative longitudinal investigation involving patients with type 1 diabetes. Diabet Med. 2012;29(8):1079-84.

44. Rankin D, et al. Supporting self-management after attending a structured education programme: a qualitative longitudinal investigation of type 1 diabetes patients' experiences and views. BMC Public Health. 2012;12(1):652.

45. Lawton J, et al. Self-treating hypoglycaemia: a longitudinal qualitative investigation of the experiences and views of people with type 1 diabetes. Diabet Med. 2013;30(2):209-15.

46. Rankin D, et al. Type 1 diabetes patients' experiences of, and need for, social support after attending a structured education programme: a qualitative longitudinal investigation. J Clin Nurs. 2014;23(19-20): 2919-27.

47. Heller $\mathrm{S}$, et al. Improving management of type 1 diabetes in the UK: the dose adjustment for Normal eating (DAFNE) programme as a research test-bed. A mixed-method analysis of the barriers to and facilitators of successful diabetes self-management, a health economic analysis, a cluster randomised controlled trial of different models of delivery of an educational intervention and the potential of insulin pumps and additional educator input to improve outcomes. Programme Grants for Applied Research. 2014;2(5).

48. Lawton J, et al. Perceptions and experiences of using automated bolus advisors amongst people with type 1 diabetes: a longitudinal qualitative investigation. Diabetes Res Clin Pract. 2014;106(3):443-50.

49. Heller $\mathrm{S}$, et al. A cluster randomised trial, cost-effectiveness analysis and psychosocial evaluation of insulin pump therapy compared with multiple injections during flexible intensive insulin therapy for type 1 diabetes: the REPOSE trial. Health Technol Assess. 2017;21(20):1-278. 
50. Snow R, Humphrey C, Sandall J. What happens when patients know more than their doctors? Experiences of health interactions after diabetes patient education: a qualitative patient-led study. BMJ Open. 2013;3(11):e003583.

51. Snow R, Sandall J, Humphrey C. Use of clinical targets in diabetes patient education: qualitative analysis of the expectations and impact of a structured self-management programme in type 1 diabetes. Diabet Med 2014;31(6):733-8.

52. Shuttlewood $E$, et al. A qualitative evaluation of DAFNE-HART: a psychoeducational programme to restore hypoglycaemia awareness. Diabetes Res Clin Pract. 2015;109(2):347-54.

53. Knight BA, et al. Qualitative assessment of user experiences of a novel smart phone application designed to support flexible intensive insulin therapy in type 1 diabetes. BMC Med Inform Decis Mak. 2016;16(1):119.

54. Fisher EB, Glasgow RE, Gabrielle JM. An Ecological Perspective on Self-Help. In: Handbook of self-help therapies; 2007.

55. Perri MG, Foreyt JP, Anton SD. Preventing weight regain after weight loss. In: Handbook of obesity: clinical applications, vol. 2; 2004. p. 185-99.

56. Corben S, Rosen R. Self-management for long-term conditions. London: King's Fund; 2005.

57. Frost J, et al. A qualitative synthesis of diabetes self-management strategies for long term medical outcomes and quality of life in the UK. BMC Health Serv Res. 2014;14(1):348.

58. Tricco AC, et al. Effectiveness of quality improvement strategies on the management of diabetes: a systematic review and meta-analysis. Lancet. 2012;379(9833):2252-61.

59. Greenwood DA, et al. A systematic review of reviews evaluating technology-enabled diabetes self-management education and support. J Diabetes Sci Technol. 2017:11(5):1015-27.

Ready to submit your research? Choose BMC and benefit from:

- fast, convenient online submission

- thorough peer review by experienced researchers in your field

- rapid publication on acceptance

- support for research data, including large and complex data types

- gold Open Access which fosters wider collaboration and increased citations

- maximum visibility for your research: over $100 \mathrm{M}$ website views per year

At $\mathrm{BMC}$, research is always in progress.

Learn more biomedcentral.com/submissions 